\title{
A origem do oceano e da atmosfera
}

\section{Introdução}

A vida não se poderia ter originado na Terra sem que o planeta tivesse adquirido uma atmosfera. A origem e primeira evolução da vida deve ter sido, de facto, grandemente influenciada pelas propriedades da atmosfera primitiva. Este artigo descreve a nossa presente compreensão de como a atmosfera surgiu e de quando este importante acontecimento ocorreu. Estas considerações também se aplicam ao oceano porque a atmosfera e oceano estão muito intimamente conjugados.

A existência de uma distinção entre oceano líquido e atmosfera gasosa é simplesmente consequência da temperatura da superfície. Se a temperatura da superfície terrestre fosse tão elevada como por exemplo a de Vénus $(700 \mathrm{~K})$, os oceanos evaporar-se-iam e teríamos uma atmosfera principalmente constituída por vapor de água. Se pelo contrário, as temperaturas fossem tão baixas como as de Marte, os oceanos congelariam, e gelo de água seria apenas um outro mineral constituinte das rochas sedimentares. A característica particular do oceano e da atmosfera é o de serem constituídos por compostos relativamente voláteis. Partilham uma história comum.

Existem duas visões contrastantes sobre a origem dos constituintes voláteis da superfície terrestre, os constituintes do oceano e da atmosfera. Uma, é a de que são primários, no sentido de serem remanescentes da nébula solar primitiva (a nuvem de gás e de poeira a partir do qual o sistema solar se originou) retidos pelo campo gravitacional da Terra desde o período da formação do sistema solar. A atmosfera de Júpiter, predominantemente constituída por hidrogénio, é primária. A outra possibilidade é a de a atmosfera e o oceano serem secundários, ho sentido em que eles foram originariamente incorporados nos componentes sólidos da Terra de onde os compostos voláteis se foram posteriormente libertando. Há poucas dúvidas de que o segundo ponto de vista é o correcto.

\section{A agregação da Terra}

Existem boas razões para se acreditar que todo o gás foi estirpado para longe no caso dos planetas interiores, provavelmente pelas radiaçð̄es do jovem Sol, deixando-os como bolas de rocha sem ar. Se bem que o seu mecanismo seja especulativo, a evidência para a perca da atmosfera primária é directa. Foi estabelecida e interpretada de uma forma razoavelmente convincente por F. R. Moulton logo em 1905. Como se mostra na figura 1, se a composição química média da Terra for comparada com a do Sol, verificamos que a Terra é extremamente deficiente em gases raros (Hélio, Neon, Argon, Cripton e Xenon), que não formam compostos nem se condensam às temperaturas que existiram no seio da nébula solar. A mensagem é clara. A Terra formou-se pela acumulação de sólidos. A componente gasosa da nébula solar não contribuiu significativamente para a massa do planeta, e qualquer atmosfera de composição nebular (ou seja de composição solar) que a Terra possa alguma vez ter possuído foi perdida. A maior parte do material que agora constitui a nossa atmosfera e oceano deve ter sido originalmente agregada na forma de compostos sólidos que terão excluído os gases inertes. As medidas das naves espaciais Viking e Vénus Pioneer mostraram que o mesmo argumento se aplica a Marte e a Vénus.

Depois da dispersão da nébula solar, os planetas destituídos de atmosfera continuaram a acumular os detritos sólidos deixados nas suas vizinhanças. Estes detritos eram uma mistura de materiais refractários que se tinham condensado quando a nébula estava quente (ou provenientes das regiões quentes da nébula) e de materiais ricos em constituintes voláteis que se condensaram tardiamente na história do arrefecimento da nébula solar (ou provenientes de regiōes frias se a variação da temperatura com o tempo não tiver sido importante). Há várias evidências que contribuem para a nossa compreensão da natureza deste material. $\mathrm{O}$ material formou-se como resultado de reacç̃̃es químicas e da condensação, que ocorreu na nébula solar a diferentes temperaturas. A teoria química pode ser usada para calcular que compostos se devem ter formado em função da temperatura. $\mathrm{O}$ ferro condensou-se às mais altas temperaturas, seguido dos minerais silicatados, dos óxidos de ferro, hidrocarbonetos e minerais silicatados hidratados.

Os compostos de maior significado para a origem do oceano e da atmosfera foram os hidrocarbonetos, compostos de hidrogénio e carbono em proporçðes variáveis, bem como a água de hidratação que se tinha combinado com alguns minerais silicatados. Os resultados teóricos são apoiados pelos estudos da composição química e mineralógica dos meteoritos, que possivelmente são representativos, até certo ponto, dos corpos sólidos que se condensaram na nébula solar e se agregaram para formar a Terra. Os constituintes voláteis mais abundantes dos meteoritos são os hidrocarbonetos e a água de hidratação, como previsto pela teoria.

\footnotetext{
* Texto adaptado de Earth History, James C. G. Walker, Jones and Bartlett Publishers, Inc., Boston, Massachussetts, a publicar em 1985. Tradução de Belarmino Salvado Barata.

Space Physics Research Laboratory, Department of Atmospheric and Oceanic Science, The University of Michigan, Ann Arbor, Michigan 48109, USA.
} 
Alguns meteoritos podem ser exemplos sobreviventes do material rico em componentes voláteis agregado pelos planetas interiores durante as fases finais do seu crescimento, do material a partir do qual as suas atmosferas se originaram.

\section{Os componentes voláteis da Terra}

Para além da teoria química e dos meteoritos, podemos analisar as camadas superficiais da Terra actual para adquirir maior conhecimento sobre o que foi agregado. O manto superior e a crusta são constituidos predominantemente de minerais silicatados compostos sobretudo de silício e oxigénio contendo magnésio, ferro, alumínio, cálcio, sódio e potássio. Minerais silicatados semelhantes são constituintes abundantes dos meteoritos e prevê-se, com base na teoria química, que eles se terão formado em abundância, a temperaturas intermédias, na nébula solar. A origem dos elementos químicos dominantes na crusta e no manto superior oferece pouco mistério. A origem dos elementos químicos que hoje se encontram no estado gasoso e líquido, na atmosfera e no oceano, necessita de maior ponderão. Em que forma sólida terão eles sido agregados pela Terra?

O composto volátil mais abundante nas camadas superficiais da Terra é a água, e a maior parte da água encontra-se no oceano. A maior parte desta água foi provavelmente agregada na forma de água de hidratação na combinação com os minerais silicatados. O aquecimento dos minerais hidratados, quer durante quer após a agregação, deve ter trazido a água para fora do interior da Terra. Água adicional deve ter sido produzida pela reacção, novamente a alta temperatura, dos hidrocarbonetos com o oxigénio combinado nos minerais silicatados ou nos óxidos de ferro que a Terra agregou juntamente com os minerais silicatados. A reacção do oxigénio com os hidrocarbonetos dá dióxido de carbono bem como água.

E, de facto, o constituinte volátil mais abudante a seguir à água é o dióxido de carbono. Este gás domina nas atmosferas de Marte e de Vénus, mas os processos geológicos fizeram com que na Terra quase todo o dióxido de carbono abandonasse a atmosfera e se integrasse na parte sólida da Terra como constituinte dos carbonatos da crusta. A massa de dióxido de carbono na crusta é cerca de um terço da massa de água nos oceanos. Os carbonatos são extremamente raros nos meteoritos e pensa-se que eles não se terão formado na nébula solar. É evidente que a Terra não agregou o dióxido de carbono na forma de carbonatos. Em vez disso, o carbono foi provavelmente agregado em combinação com o hidrogénio nos hidrocarbonetos já mencionados. Este carbono ter-se-ia libertado para a atmosfera como dióxido de carbono quando os hidrocarbonetos foram oxidados, a alta temperatura, na reacção que já foi mencionada como uma fonte de água. Uma sugestão alternativa, da autoria de J. S. Lewis, é a de que o carbono na sua forma elementar estaria misturado com o ferro metálico que agora forma o núcleo da Terra.

$\mathrm{O}$ azoto, o constituinte dominante da atmosfera terrestre, é cerca de 100 vezes menos abundante que o dióxido de carbono quando os carbonatos da crusta são contabilizados. Quase todo o azoto terrestre está na atmosfera. Não se crê que tenha formado compostos sólidos na nébula solar e é virtualmente indetectável nos meteoritos. Evidentemente o azoto foi agrega- do como um contaminante menor da matéria sólida que formou as camadas superficiais da Terra. É provável que devamos a presença do azoto na Terra a imperfeições nos processos químicos e de condensação ocorridos na nébula solar. O amoníaco, um composto de azoto e hidrogénio, toma ocasionalmente o lugar do potássio nas redes cristalinas dos silicatos porque os tamanhos da molécula de amoníaco e de um átomo de potássio são quase os mesmos. Um erro químico semelhante tornou provavelmente possível a agregação do cloro que agora corresponde a um dos componentes dissolvidos mais abundantes do mar (o sal marinho é o cloreto de sódio, $\mathrm{NaCl}$ ).

O cloro pode ter substituido ocasionalmente o oxigénio nas redes cristalinas dos silicatos. Estes elementes errantes, que trespassam estruturas químicas a que não pertencem, ter-se-iam libertado quando as rochas nas quais se incorporaram fundiram e então se recristalizaram.

\section{Desgasificação}

O processo pelo qual os gases foram libertados da Terra sólida para formarem a atmosfera e o oceano é conhecido como desgasificação. Duas condições tiveram que ser conseguidas para a ocorrência da desgasificação. Primeiro, os materiais ricos em constituintes voláteis tinham de ser sujeitos a temperaturas relativamente elevadas de forma a libertarem os gases dos sólidos por fusão e por reacção química. Em segundo lugar, os gases produzidos pelas reacções a altas temperaturas no seio da Terra tinham de alguma forma de ser trazidos à superfície - as camadas superficiais da Terra tinham de ser revolvidas.

Quando e como a desgasificação ocorreu é ainda objecto de debate. O ponto de vista tradicional, primeiramente desenvolvido por William W. Rubey do United States Geological Survey em 1951, sustenta que a desgasificação foi gradual; tomou lugar ao longo da história geológica através dos vulcões e fontes de água quente tal como as encontramos hoje na Terra. De acordo com este ponto de vista, as massas atmosféricas e oceânicas cresceram gradualmente com o tempo e provavelmente ainda estão a crescer. $\mathrm{O}$ ponto de vista alternativo, apresentado mais energicamente por Fraser Fanale do Jet Propulsion Laboratory em 1971, sustenta que houve um único e curto episódio de desgasificação que ocorrem no início da história da Terra.

Há várias linhas de evidência que apoiam a noção de uma rápida e primitiva desgasifícação. É provável, contudo, que a verdade esteja algures entre estes limites. A maior parte da atmosfera e do oceano terrestres pode ter sido libertada num episódio primitivo de desgasificação rápida, mas o processo pode nunca ter parado no seu conjunto.

Uma das mais atraentes características da hipótese de uma primitiva e rápida desgasificação é a de fazer uso de uma abundante fonte de energia para o necessário aquecimento e revolver das superfícies exteriores. Esta energia foi fornecida pelo bombardeamento da Terra por material sólido durante os estágios finais da agregação. A desgasificação provavelmente teve lugar durante as últimas fases do crescimento do planeta.

Extensas áreas da Lua, Marte e Mercúrio estão cobertas de terreno cheio de crateras que se formou durante a agregação das camadas superficiais. Mesmo sobre a Terra, onde pouca crusta antiga sobreviveu à fúria das actividades erosiva e tectónica (formação de 
montanhas), podem ser encontrados restos de antigas crateras de impacto. Estudos da Lua pelas missões Appolo revelaram que a maior parte das crateras lunares foram formadas há mais de 3.8 mil milhões de anos. A agregação das camadas superficiais dos planetas parece ter ficado praticamente completa por essa altura.

Possivelmente não por coincidência, as rochas mais antigas que conhecemos à superfície da Terra, perto de Isua em West Greenland, datam desta altura. Estas rochas foram profundamente metamorfoseadas por altas temperaturas e pressões após a sua formação, mas pelo menos algumas destas foram depositadas originalmente, como sedimentos no fundo do mar. Isto é um dado muito significativo. Confirma que a Terra tinha adquirido algum oceano e atmosfera antes de completar um milhar de milhão de anos, embora deixe em aberto a questão da extensão deste oceano e desta atmosfera.

\section{Conclusão}

O pensamento moderno sustenta, portanto, que a Terra agregou os constituintes da atmosfera e do oceano na forma de compostos sólidos juntamente com os constituintes que hoje formam o corpo sólido do planeta. $\mathrm{O}$ aquecimento e a perturbação das camadas superficiais durante os estágios finais da agregação da Terra expulsaram elementos e compostos voláteis para fora da fase sólida, para a atmosfera e o oceano. Este

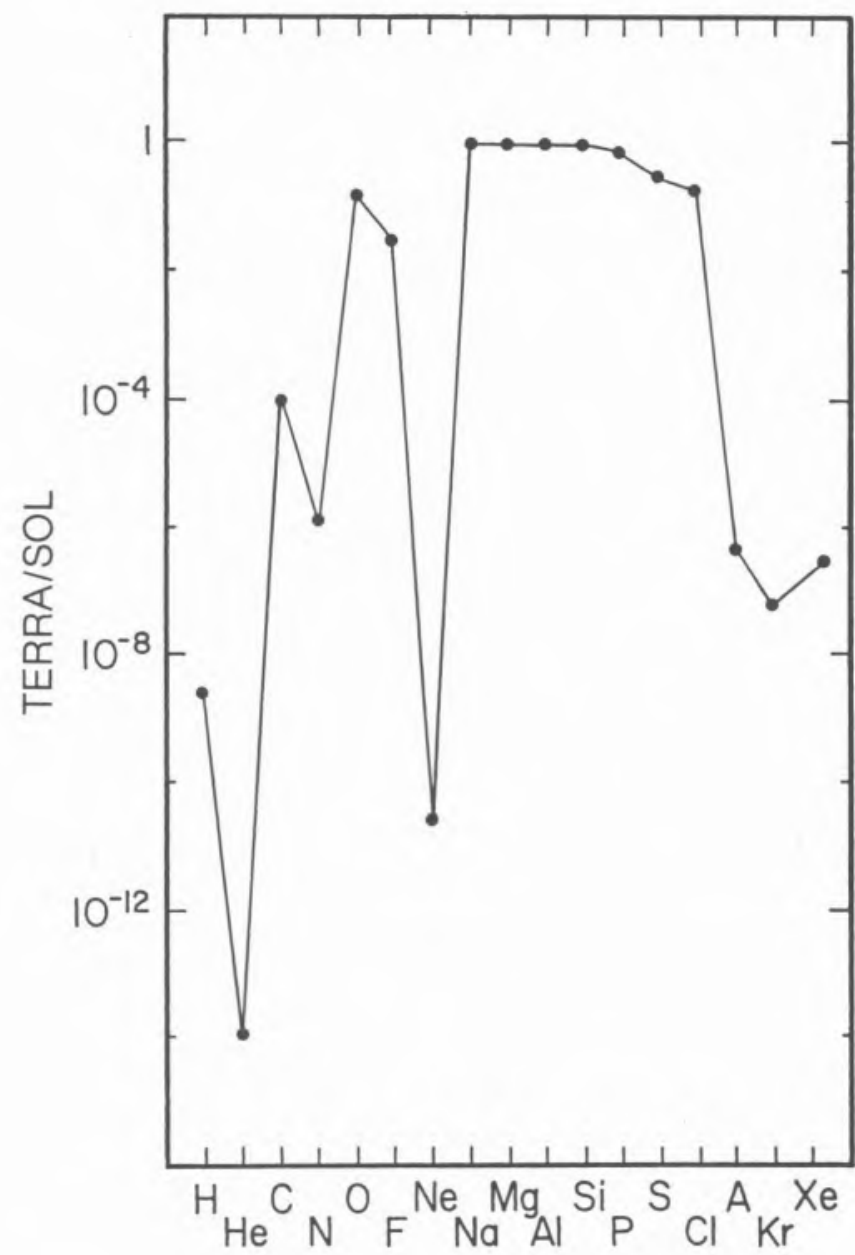

Figura 1

Abundâncias dos diferentes elementos na Terra em relação às abundâncias solares processo de desgasificação ocorreu provavelmente ao mesmo tempo que a formação da Terra. Os constituintes libertados mais abundantes foram o vapor de água e o dióxido de carbono, com quantidades mínimas de enxofre e de cloro. O vapor de água condensou-se largamente para formar o oceano enquanto o dióxido de carbono reagiu com as rochas para formar os carbonatos dos sedimentos. Por altura da origem da vida terrestre, a atmosfera pode ter sido constituída sobretudo por azoto, que não tende a penetrar em fases sólidas ou líquidas nas condições da superfície da Terra.

\section{SUGESTÕES DE LEITURA}

Brancazio, P.. J. and Cameron A. G. W. (Eds.), The Origin and Evolution of Atmospheres and Oceans, John Wiley and Sons, New York, 1964.

Chapman, C. R., The Inner Planets, Charles Scribner's Sons, New York, 1977.

Goody, R. M. and Walker J. C. G., Atmosferas Planetárias (Tradução António Christofoletti), Editora Edgard Blucher Ltda. São Paulo, Brasil, 1975.

Lewis, J. S. and Prinn R. G., Planets and Their Atmospheres, Academic Press, New York, 1984.

Walker, J. C. G., Formation of the inner planets, Monthly Notes of the Astronomical Society of Southern Africa, 35, 2-8, 1976.

Walker, J. C. G., Evolution of the Atmosphere, $318 \mathrm{pp}$, Macmillan, New York, 1977.

Walker, J. C. G., Origin of the atmosphere: History of the release of volatiles from the solid earth, in Chemical Evolution of the Early Precambrian, edited by C. Ponnamperuma, pp. 1-11, Academic Press, New York, 1977.

Walker, J. C. G., Evolution of the chemical composition of the atmosphere, Impact of Science on Society, 32, 261-269, 1982.

Walker, J. C. G., How life affects the atmosphere, BioScience, 34, 486-491, 1984.

\section{EDIÇÕES ALMEDINA}

\section{- BIOLOGIA FUNCIONAL}

Por Arsélio Carvalho - Caetano Carvalho - Francisco Ferrand - Vitor Almeida - António Nobre - Euclides Pereira

Prof. de Zoologia da Universidade de Coimbra

- O MUNDO DOS ÁTOMOS

Por Maria Helena Côncio

ÁTOMOS EM COMPETIÇÃO

Por Maria Helena Côncio

ORIGENS DA VIDA (Do Átomo à Célula)

Por Joël Rosnay

- TERMODINÂMICA

Por Enrico Fermi

- VAMOS COMPREENDER A TERRA

Por J.G. Goss; Petter Smith; R.C.L. Wilson

- FUNDAMENTOS DE TERMODINÂMICA QUIMICA

Por E. Brian Smith

\section{- O QUADRO PERIÓDICO DOS ELEMENTOS \\ Por R.J. Puddphatt}

\section{- A FORMA E A ESTRUTURA DAS MOLÉCULAS \\ Por C.A. Coulson}

- POLUIÇÃO DO MEIO AMBIENTE

Por Maria Fernanda Correia Cardoso 